\title{
Editorial
}

\section{From Modems to Mobile Apps}

\section{Web-Based Research in Psychology}

\author{
Ulf-Dietrich Reips ${ }^{1}$ and Tom Buchanan ${ }^{2}$ \\ ${ }^{1}$ Psychological Methods and Assessment / Experimental Psychology and Internet Science, Department of Psychology, \\ University of Konstanz, Germany \\ ${ }^{2}$ School of Social Sciences, University of Westminster, London, UK
}

Web-based research in psychology became possible with the development of the world wide web in the early 1990s. While at first, only a few people began using web browsers, now more than half of humanity uses a browser every day, providing them with easy access to participate in science. Traditional laboratory-based and field methods were transformed, adapted, studied, and scaled to apply to the online environment properly. Different methods and new possibilities for research emerged, quantitatively and qualitatively, leading for example, directly to Open Access and Open Science. As with other methods in psychology, web-based research methodology has evolved since and has increased and diversified with layers upon layers of new major developments in Internet technology and life (e.g., Google search; "Web 2.0"; social media; smartphones; automated agents; intensive and Big Data; Open Science). The articles in this special issue are a selection of state-of-the-art pieces on and of web-based research in psychology.

In the first article, Reips (2021) reviews different types of web-based research, including research that could not be done without the web. He highlights how some specific research areas, for example, on the rare disorder sexsomnia, have profited enormously from the advantages of the web, in this case the combination of reach and anonymity. Reips describes and discusses methods and techniques in web-based research and summarizes the literature that has used these. He moves on to pitfalls and best practices in web-based research, for example, the disastrous fall of large portions of psychology for dubious recruitment platforms, the phenomenon of "embedded scientists" with dominant social media companies, ever-increasing technological complexity, and the helpful role web-based research can play in Open Science. Reips describes how these research practices have changed over time in a technologically and culturally dynamically changing web environment, with milestones such as the appearance and growth of search engines, social media, and mobile smartphones. Confirming an early observation (Buchanan \& Reips,
2001), he throws a light on the interaction of psychology (e.g., personality) and technology. Thus, beyond Rosenthal and Rosnow's (1975) analysis of volunteerism of participants in psychological research, more is to be considered in web-based research that leads deep into the complexity of technology preferences, access, customization (even on a physiological level), and into an intertwined web of technology and active experience in daily life.

In their Original Article, Altmann and Kapoor (2021) focus on factors that might influence how people complete unsupervised personality questionnaires online. The impact this might have on data quality was a major focus of interest in the early days of web-based behavioral science. This article shows that there are still things to be learned. For example, levels of extraversion were lower for participants who chose to complete a personality questionnaire in the early afternoon, as opposed to the morning. However, the finding that data quality was not much affected by the time of day and type of device used to participate gives confidence in using online personality tests.

As well as research methodology, some of the articles address research ethics. Ethical issues are as pertinent to web-based methods as they are to all research. However, there are special characteristics of online research environments that raise ethical concerns. In their Original Article, Hilbig and Thielmann (2021) focus on one particularly troubling issue: deception. They point out ways in which deception can be even more problematic in web-based research than in offline work (e.g., due to drop-out before debriefing). They argue that this presents significant ethical problems and provide data showing that deception in online studies is relatively common. Their primary recommendation is that deception should not be used in web-based research, but they also provide suggestions for ways to implement deception that are more compliant with our discipline's codes of research ethics. While some of their conclusions and recommendations may be controversial, this paper shines a light on a genuinely important issue. 
In a journal that Hermann Ebbinghaus co-founded, it is more than appropriate and fortunate to include an article that features his work. In his Research Spotlight, Krantz (2021) describes a web-based replication of a perception experiment on what is now well-known as the Ebbinghaus illusion. His example - which the reader can access via a URL and Open Science archive - highlights the benefits and challenges of the technical variation commonplace in web-based research and how the web may help advance our knowledge in perception research.

Krantz's article also exemplifies the slow revolution currently occurring in the research community, as many people move to adopt "Open Science" practices. Sharing of research materials is something that early adopters of web-based research championed (see e.g., Birnbaum, 2021; Reips, 2002, Standard 16). A number of the other articles in this issue adopt various Open Science practices, including sharing data, materials, and preregistrations.

A good example of this is Huber and Artemenko's (2021) Research Spotlight. In their article, the authors use a selection of tools and platforms for preregistration and sharing data and materials that have been developed using the open-source tool jsPsych. Anxiety about mathematics affects performance on arithmetical tasks, with more interference in more complex tasks. The article shows that this previously established effect is replicable in a web-based protocol, and demonstrates the power of web-based methods to recruit diverse samples.

While some of the contributions rely on "traditional" research techniques that have been adapted for use online, others deal with newer methods that have only become possible since the development of the web. Speckmann's (2021) Research Spotlight deals with techniques allowing the analysis of online behavioural traces. Speckmann outlines basic principles of this approach, and demonstrates step-by-step how it can be used with a practical example from his own research. He also makes some comments on practical and ethical considerations. Links to further resources are provided for those who might wish to pursue this method.

Some past authors have decried psychology's movement toward self-report and questionnaire measures rather than direct behavioral measurements (e.g., Baumeister et al., 2007). This predated, but is very likely to have been exacerbated by, the growth of web-based methods: a growth leading to what has been characterized as "MTurkification" (Anderson et al., 2019). However, there is plenty of space for behavioral observations in web-based research. A good example of this is provided by Freihaut and Göritz in their Research Spotlight (2021). Using a combination of online and offline studies, they seek to establish whether participants' typing behavior could be used as an index of stress levels. Part of the value in this paper is showing what does not work - useful in preventing other researchers from pursuing fruitless methodological approaches.

In the fifth Research Spotlight, Zapf et al. (2021) report on their investigation of whether the ratings of products in web-based review platforms replicate the common finding that people are less likely to share minority views. They tracked online reviews of 76 products on a web-based shopping platform over 6 weeks and found the opposite, namely that people were more likely to share minority than majority views. They discuss whether the findings falsify the applicability of social psychological theories to product ratings or whether web-based rating format, definitions that were chosen in measurement, and the online environment and review-related policies by the vendor may have contributed to the results.

Another ethically important general issue, accessibility, is discussed by Vereenooghe (2021) in her Opinion article. She aims at raising awareness of the chances and challenges of inclusiveness in web-based research and reminds us of both the ethical obligation to do science for everyone and the methodological and epistemological issues of limiting research to narrow participant groups. Her article contains useful pointers to resources and technological advances and reiterates arguments long put forward by the pioneers of web-based research that a "key benefit to researchers is that it offers them more opportunities to reach special or hard to reach populations".

Birnbaum (2021) describes in his Horizon article a series of Advanced Training Institutes and summer schools on web-based research in psychology that were given and attended by many researchers who then began using the web in their work. These ongoing educational efforts spanning from the late 1990s over the decades into the future reflect web-based methods and techniques as they change over time. He reflects on technology that is no longer functional today and how such changes influenced methodology, features, and progress of web-based research. He concludes with lessons learned that can be used to anticipate and plan future directions in web-based research.

One future direction for web-based research outlined by Honing (2021) in his Horizon article is more gaming and entertainment. Honing shows how the area of music cognition is well-suited for engaging participants and - due to sampling dependency and individual variability - in need of large samples. He exemplifies some advantages of web experimentation over laboratory experimentation.

Web-based research in psychology has flourished (e.g., Krantz \& Reips, 2017) and is, again and again, giving birth to new opportunities for research. Each technological milestone creates a new layer in the web and provides new ground for creative researchers to find nifty ways and methods of conducting studies to advance psychological science. 
As researchers who have closely witnessed and cocreated the web revolution in research we stand with amazement and unbroken spirit upon its breathtaking opportunities and dynamic change. However, we are sometimes concerned about how naively new technologies are adopted in breaking the eternal principles of science and how slowly the scientific community sometimes realizes challenges within. One promise of web-based research had been the return to 18th century independence of researchers from institutions (Reips, 1997), but instead, it took just a few years for large portions of psychological research to switch to practices that outsourced the interaction with participants to commercial platforms via the web and created "embedded scientists" - thus an even higher dependency on institutions with aims differing from those in research and a removal from direct experience with the core subject of our science: the human. As psychologists using the web for research, it is up to us all to ensure that we maintain high levels of methodological rigor and scientific integrity. We hope that the material included in this special issue will contribute toward that aim.

\section{References}

Altmann, T., \& Kapoor, N. (2021). Personality assessment to-go: Formal aspects of unproctored web-based personality assessment in relation to its content and quality. Zeitschrift für Psychologie, 229(4), 214-224. https://doi.org/10.1027/21512604/a000465

Anderson, C. A., Allen, J. J., Plante, C., Quigley-McBride, A., Lovett, A., \& Rokkum, J. N. (2019). The MTurkification of social and personality psychology. Personality and Social Psychology Bulletin, 45(6), 842-850. https://doi.org/10.1177/0146167218798821

Baumeister, R. F., Vohs, K. D., \& Funder, D. C. (2007). Psychology as the science of self-reports and finger movements: Whatever happened to actual behavior? Perspectives on Psychological Science, 2(4), 396-403. https://doi.org/10.1111/j.1745-6916. 2007.00051.x

Birnbaum, M. H. (2021). Advanced training in web-based psychology research: Trends and future directions. Zeitschrift für Psychologie, 229(4), 260-265. https://doi.org/10.1027/21512604/a000473

Buchanan, T., \& Reips, U.-D. (2001). Platform-dependent biases in online research: Do Mac users really think different? In K. J. Jonas, P. Breuer, B. Schauenburg, \& M. Boos (Eds.), Perspectives on Internet research: Concepts and methods. http://www. uni-konstanz.de/iscience/reips/pubs/papers/Buchanan_ Reips2001.pdf

Freihaut, P., \& Göritz, A. S. (2021). Does peoples' keyboard typing reflect their stress level: An exploratory study. Zeitschrift für Psychologie, 229(4), 245-250. https://doi.org/10.1027/21512604/a000468
Hilbig, B. E., \& Thielmann, I. (2021). On the (mis)use of deception in web-based research: Challenges and recommendations. Zeitschrift für Psychologie, 229(4), 225-229. https://doi.org/ 10.1027/2151-2604/a000466

Honing, H. (2021). Lured into listening: Engaging games as an alternative to reward-based crowdsourcing in music research. Zeitschrift für Psychologie, 229(4), 266-268. https://doi.org/ 10.1027/2151-2604/a000474

Huber, J. F., \& Artemenko, C. (2021). Anxiety-related difficulties with complex arithmetic: A web-based replication of the anxiety-complexity effect. Zeitschrift für Psychologie, 229(4), 236-240. https://doi.org/10.1027/2151-2604/a000469

Krantz, J.H. (2021). Ebbinghaus illusion: Relative size as a possible invariant under technically varied conditions? Zeitschrift für Psychologie, 229(4), 230-235. https://doi.org/ 10.1027/2151-2604/a000467

Krantz, J., \& Reips, U.-D. (2017). The state of web-based research: A survey and call for inclusion in curricula. Behavior Research Methods, 49(5), 1621-1629. https://doi.org/10.3758/s13428017-0882-x

Reips, U.-D. (1997). Forschen im Jahr 2007: Integration von Web-Experimentieren, Online-Publizieren und MultimediaKommunikation [Science in the year 2007: Integration of web experimenting, online publishing, and multimedia communication]. In D. Janetzko, B. Batinic, D. Schoder, M. Mattingley-Scott, \& G. Strube (Eds.), CAW-97. Beiträge zum Workshop "Cognition \& Web" (pp. 141-148). IIG-Berichte 1/97.

Reips, U.-D. (2002). Standards for Internet-based experimenting. Experimental Psychology, 49(4), 243-256. https://doi.org/ 10.1026//1618-3169.49.4.243

Reips, U.-D. (2021). Web-based research in psychology: A review. Zeitschrift für Psychologie, 229(4), 198-213. https://doi.org/ 10.1027/2151-2604/a000475

Rosenthal, R., \& Rosnow, R. L. (1975). The volunteer subject. Wiley. Speckmann, F. (2021). Web scraping: A useful tool to broaden and extend psychological research. Zeitschrift für Psychologie, 229(4), 241-244. https://doi.org/10.1027/2151-2604/a000470

Vereenooghe, L. (2021). Participation of people with disabilities in web-based research. Zeitschrift für Psychologie, 229(4), 257259. https://doi.org/10.1027/2151-2604/a000472

Zapf, B., Hütter, M., \& Sassenberg, K. (2021). Are minority opinions shared less? A conceptual replication using web-based reviews. Zeitschrift für Psychologie, 229(4), 251-256. https://doi.org/10.1027/2151-2604/a000471

Published online December 17, 2021

\section{Funding}

Open access publication enabled by Hogrefe Publishing.

\section{Ulf-Dietrich Reips}

Department of Psychology

University of Konstanz

Universitätsstraße 10

Fach 31

78464 Konstanz

Germany

reips@uni-konstanz.de 